\title{
Healthcare spending and health outcomes: evidence from selected East African countries
}

\author{
Murad A.Bein ${ }^{1}$, Dogan Unlucan², Gbolahan Olowu ${ }^{1}$, Wagdi Kalifa ${ }^{2}$
}

1. Faculty of Economics and Administrative Sciences, Cyprus International University, Lefkosa, Turkey

2. Faculty of Business and Economics, Eastern Mediterranean University Famagusta, Turkey

\begin{abstract}
Background: Over the last decade, total healthcare expenditures, comprised of both public and private healthcare expenditures, have increased in most East African countries. At the same time, health outcomes such as infant mortality rates, life expectancy at birth and other health outcome indicators have improved.

Objectives: This paper examines the association between healthcare expenditures and health outcomes for eight East African countries: Burundi, Eritrea, Ethiopia, Kenya, Rwanda, Sudan, Tanzania, and Uganda. In this study, health outcomes are defined as an improvement in adult life expectancy and a reduction in the number of neonatal, infant, and under-five deaths.

Methods: We implemented a panel data regression technique, analyzing both cross-sectional and time series information. This combined method has been used in healthcare studies by several authors. Data obtained from world development indicators for the years 2000-2014 was used for the panel study.

Results: First, we documented that there is a strong, positive association between total healthcare expenditures and total life expectancy. While we identified a positive relationship between healthcare expenditures and female and male life expectancy, we found that healthcare had a stronger effect on improving life expectancy in females than in males. Moreover, we found a negative relationship between healthcare expenditures and the number of neonatal, infant, and under-five deaths.

Conclusion: The results of this study have important policy and management implications for the eight East African countries. From a policy perspective, it is necessary to understand if a greater allocation of resources to the healthcare sector is worthwhile and to determine whether to encourage private healthcare investment. From the management perspective, investing in more private institutions, such as hospitals and clinics, is essential for health outcomes in the average country. The results of this study can be used by the World Health Organization as well as other non-governmental organizations that provide financial assistance to East African countries.
\end{abstract}

Keywords: Healthcare expenditures, health outcome, life expectancy, infant deaths, under-five deaths, neonatal deaths.

DOI: https://dx.doi.org/10.4314/ahs.v17i1.30

Cite as: Bein $M A$, Unlucan D, Olown G, Kalifa W. Healthcare spending and health outcomes: evidence from selected East African countries. Afri Health Sci. 2017;17(1): 247-254. https:// dx.doi.org/10.4314/abs.v17i1.30

\section{Introduction}

Understanding total healthcare expenditures, comprised of both public and private healthcare expenditures, as share of total gross domestic product (GDP), is crucial for effective policy-making at the national and regional levels. Over the last decade, healthcare expenses have increased in most East African countries. Figure 1 shows healthcare expenditures as a share of GDP among eight East African countries (Burundi, Eritrea, Ethiopia, Ken-

\section{Corresponding author:}

Murad A.Bein,

Department of Accounting and Finance

Faculty of Economics and Administrative Sciences

Cyprus International University

Lefkosa, North Cyprus, via Mersin 10, Turkey

Email: mbein@ciu.edu.tr ya, Rwanda, Sudan, Tanzania, and Uganda) between 1995 and 2014. It is evident that there is an upward trend in expenditures for almost all of the countries save Eritrea, where healthcare costs have remained relatively low with only slight increases over time. However, along with these increases in healthcare expenditures have been improvements in health outcomes including infant mortality rates, life expectancy at birth and other health outcome indicators. Table 1 demonstrates that in the last 15 years, Burundi, Eritrea, Ethiopia, Kenya, Rwanda, Sudan, Tanzania, and Uganda all exhibited considerable progress in increasing life expectancy and in reducing the number of neonatal, infant and under-five deaths. The highest increase in life expectancy (15.77) years is observed in Rwanda, whereas Ethiopian has achieved the highest reduction in number of neonatal (52515), infant (126816), and under-five deaths (223147).

African Health Sciences Vol 17 Issue 1, March, 2017 
Given these concurrent trends, we aim to empirically determine whether there is a definitive relationship between healthcare expenditures and health outcomes for East African countries. We selected East African countries because many of these countries have experienced political and social unrest, and east Africa has been the most volatile region in Africa. As expected, it was the region with the high mortality rate and lower life expectancy (unfortunately, we could not include Djibouti, Somalia, and South Sudan in this study due to the lack availability of data). However, recently, almost all East African countries have witnessed moderate stability. Thus, policymakers have been able to focus more on improving healthcare, as demonstrated by the increasing healthcare expenditures (Figure 1) and the improvements in health outcomes (Table 1). The results from this investigation could provide important implications for implementing effective and efficient policymaking with respect to healthcare expenditures. These results can also be applied to other developing economies, especially to those that have higher neonatal, infant mortality rates and lower life expectancies.

In this study, we define health outcomes as adult life expectancy and number of neonatal, infant and under-five deaths. In the existing literature, many researchers have investigated the association between healthcare spending and health outcomes ${ }^{1-14}$. Other authors have examined the relationship between healthcare spending and life expectancy. Using panel data, Jaba et al. ${ }^{15}$ examined the relationship between healthcare expenditures (input) and life expectancy (as a proxy for heath outcomes) for 175 countries from 1995to 2010. Their findings revealed an association between life expectancy and healthcare expenditures. Aisa et al. ${ }^{16}$ also found that an increase in healthcare expenditures leads to improved life expectancy. In line with these studies, Akinci et al. ${ }^{17}$ investigated the relationship between healthcare expenditures and health outcomes (defined as an improvement in infant, under-five, and maternal mortality) for Middle Eastern and Northern African countries using yearly data from 1990 to 2010. They found that increases in total healthcare expenditures reduce infant, under-five, and maternal mortality rates. Moreover, Anyanwu and Erhijakpor ${ }^{18}$ examined healthcare expenditures and health outcomes (infant mortality and under-five mortality) for 47 African countries in the period between 1999 and 2004. Their results were based on econometric analysis, and they found a statistically significant relationship between healthcare expenditures and health outcomes; however, the relationship was region-dependent. For Sub-Saharan African countries, they documented a positive relationship, yet for Northern Africa, the results indicated a negative relationship between healthcare expenditures and health outcomes.

Mays and Smith ${ }^{19}$ analyzed the relationship between the increase in government healthcare expenditures and preventable deaths, particularly those related to infant mortality, cardiovascular disease, diabetes, and cancer. They empirically showed that a 10 percent increase in local public healthcare spending led to a decline in infant mortality between 1.1 and 6.9 percent and argued that the increase in public healthcare spending has a long-lasting impact on low-resource communities. Other researchers have examined associations between public healthcare expenditures and other variables. Maruthappu et al. ${ }^{20}$ studied the relationship between unemployment, public healthcare expenditures, and HIV mortality for 74 countries using yearly data from 1981 to 2009. Their results show that an increase in public health spending is negatively correlated with HIV mortality and further demonstrated that an increase in unemployment is associated with an increase in HIV mortality.

In addition to studies of the relationship between healthcare expenditures and health outcomes in Middle Eastern and African countries, many researchers have attempted to examine this association in European countries. For example, Nixon and Ulmann ${ }^{21}$, examined the relationship between healthcare spending and health outcomes for 15 European countries using yearly data from 1980to 1995 and employing fixed panel techniques. They demonstrated that increased healthcare expenditures reduce mortality rates, but, in line with the aforementioned studies, showed limited impact on life expectancy. Accordingly, Vavken et al..$^{22}$, used ordinary least squares, two stage least squares, and Prais-Winsten estimation to examine if an increase in total healthcare expenditures could enhance health outcomes for Austrians. They found that an increase in healthcare expenditures reduces mortality, cardiovascular disease, injury, poisoning, and malignant disease. 
Other authors have also studied the relationship between healthcare spending and health outcomes by including the role of governance and education. For example, Farag et al. ${ }^{23}$ explored the role of good governance on the relationship between healthcare expenditures and health outcomes for 133 developed and developing economies. Their empirical work documented that healthcare spending reduced infant and under-five child mortality; they also provided evidence that in countries with good governance, the government healthcare expenditures had an impact in reducing these mortality figures. Gupta et al. ${ }^{24}$ studied the effect of government spending on the education and healthcare of 50 transition economies. They demonstrated that an increase in government expenditure on education and healthcare contributed to an increase in the number of people attending school and a reduction in mortality rates for infants and children. Several studies have examined the impact of government healthcare expenditures on health outcomes ${ }^{25-26}$. Many researchers have also assessed the impact of private healthcare expenditures ${ }^{27-29}$.

Though they have yielded several useful insights, none of the aforementioned studies considered East African countries, and although Anyanwu and Erhijakpor ${ }^{18}$, examined all African countries, their sample study ended in 2004. They also did not consider life expectancy at birth and number of neonatal deaths as health outcomes and instead focused solely on infant and under-five mortality. Therefore, an empirical investigation regarding the rela- tionship between healthcare expenditures and health outcomes in East African countries is necessary.

This paper differs from existing studies in several ways. First, we study East African countries that are experiencing fast population and moderate economic growth. Second, we make use of the most recent data to investigate the relationship between healthcare expenditures and health outcomes. Finally, we analyze the relationship between healthcare expenditures and health outcomes using a fixed effects regression, studying the variables in both a cross-sectional and time series manner.

The findings of this paper are as follows: first, we found a positive relationship between healthcare expenditures and life expectancy at birth. The relationship was robust for both female and male life expectancy although the results revealed a stronger correlation between healthcare expenditures and life expectancy for females. Second, the results indicate a negative relationship between healthcare expenditures and the number of neonatal, infant, and under-five deaths. Thus, an increase in government and private healthcare expenditure reduces neonatal, infant, and under-five deaths. Overall, increase in healthcare expenditure is associated with an increase in life expectancy by and a reduction in the number of infant deaths, under-five deaths and number of neonatal deaths.

The remainder of this paper is organised as follows: section two discusses the data and methodology, section three discusses the empirical findings, and section four provides conclusions and policy recommendations.

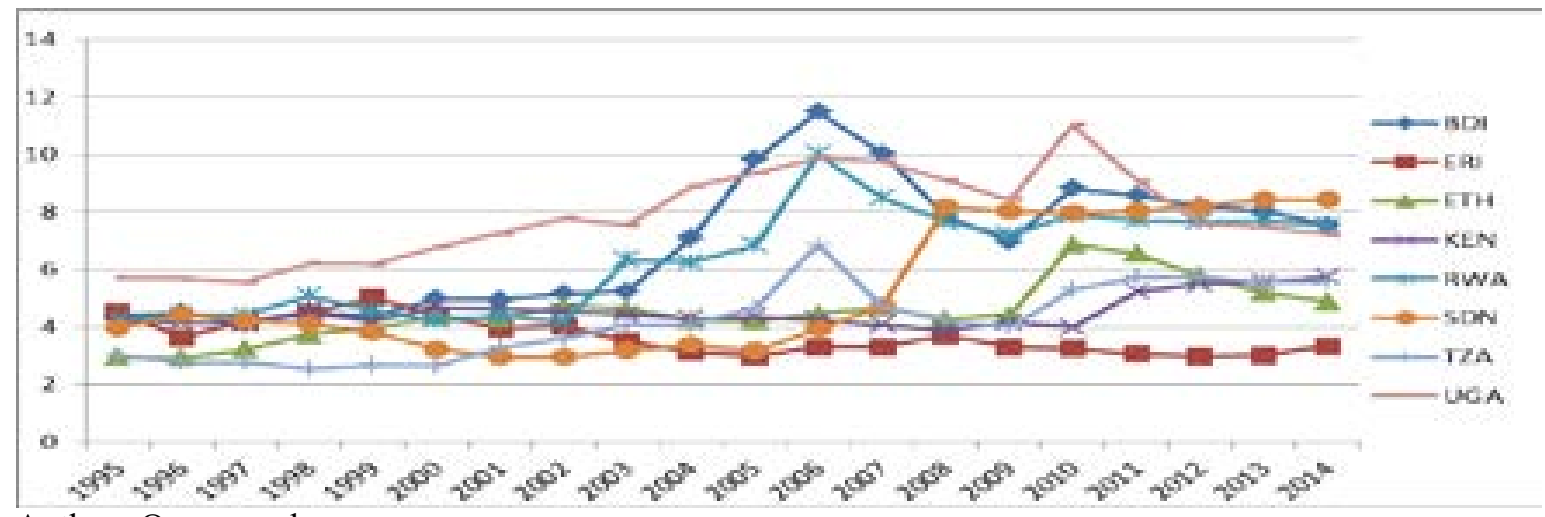

Authors Owen work.

Figure 1: Healthcare expenditures as a share of GDP 


\begin{tabular}{|l|l|l|l|l|}
\hline \multicolumn{6}{|l|}{ Table 1: Health outcomes in East African countries } \\
\hline Countries & LE & NID & NUFD & NOD \\
\hline Burundi & 5.20654 & -622 & -4664 & 2374 \\
\hline Eritrea & 7.638 & -1442 & -2901 & -150 \\
\hline Ethiopia & 12.1047 & -126816 & -223147 & -52515 \\
\hline Kenya & 10.7912 & -22720 & -46149 & 471 \\
\hline Rwanda & 15.7733 & -27493 & -45583 & -8286 \\
\hline Sudan & 5.48356 & -10826 & -21288 & 429 \\
\hline Tanzania & 14.4786 & -35186 & -73860 & -4168 \\
\hline Uganda & 12.0464 & -37841 & -73374 & -5651 \\
\hline
\end{tabular}

Authors calculation obtained by deducting the year 2000 from year 2014 (2000-2014). All the data are from World Bank indicators.

Life expectancy at birth in total (years) is represented by LE, number of infant deaths by NID, number of under-five deaths by NUFD, and number of neonatal deaths by NOD.

\section{Data and methodology}

\section{Data}

This study utilizes data from several world development indicators' annual data from 2000 to 2014. The variables used in this study are listed in Table 2. The table also shows descriptive statistics of these variables, including the number of observations, means, standard deviations, and minimum and maximum numbers. Moreover, Table 2 shows that our data is free of outliers, which allows us to make useful conclusions based on the data.

\section{Methodology}

We utilized panel data techniques that consider individu- ality and time variation. We make use of the Fixed effect method to examine the relationship between healthcare spending and health outcomes. This method has several advantages in that it addresses individuality, as each of the eight countries have different structures and systems including economies, welfare state schedules, geographical aspects, and national health systems (30). Several authors of healthcare studies have investigated the relationship between healthcare expenditures and health outcomes using the Fixed effect method (31-32). The specific equations that we used for regression analysis are models 1 through 6 .

Model 1:

$L E T=\alpha_{i}+\beta_{1} H E_{i t}+\varepsilon_{i t}$

Model 2:

$L E F=\alpha_{i}+\beta_{1} H E_{i t}+\varepsilon_{i t}$

Model 3:

$L E M=\alpha \alpha_{i}+\beta_{1} H E_{i t}+\varepsilon_{i t}$

Model 4:

$L N I D=\alpha_{\mathrm{i}}+\beta_{1} H E_{\mathrm{it}}+\varepsilon_{\mathrm{it}}$

Model 5:

LNOUFD $=\alpha_{\mathrm{i}}+\beta_{1} H E_{i t}+\varepsilon_{i t}$

Model 6:

$L N O N=\alpha_{i}+\beta_{1} H E_{i t}+\varepsilon_{i t}$

Definitions of the variables are as follows: $i=1 \ldots . . n$ ( $n-$ the number of countries), $t=1 \ldots \ldots T$ ( $\mathrm{T}$ - the number of periods), $i$ is a fixed effect parameter that can vary across individual countries but does not vary over time. The dependent variable is healthcare expenditure share of GDP (HE), while independent variables are life expectancy at birth (LET), male life expectancy at birth (LEM), female life expectancy at birth (LEF), number of infant deaths (LNID), number of under-five deaths (LNOUFD), and number of neonatal deaths (LNON). 
Table 2: Descriptive statistics

\begin{tabular}{|l|l|l|l|l|l|}
\hline Variable & Obs & Mean & Std. Dev. & Min & Max \\
\hline HE & 120 & 5.790651 & 2.153943 & 2.641686 & 11.49013 \\
\hline LET & 120 & 57.03446 & 4.448819 & 46.41998 & 64.9439 \\
\hline LEM & 120 & 55.24935 & 4.486825 & 42.887 & 63.54 \\
\hline LEF & 120 & 58.90882 & 4.700511 & 47.555 & 67.025 \\
\hline LNID & 120 & 10.73827 & 0.9877643 & 8.662332 & 12.46778 \\
\hline LNOUFD & 120 & 11.14548 & 1.010453 & 8.986947 & 12.93188 \\
\hline LNON & 120 & 10.06001 & 1.017321 & 8.043021 & 11.85911 \\
\hline
\end{tabular}

\section{Empirical results}

Tables 3 through 6 present the results from the investigation regarding the relationship between healthcare expenditures and health outcomes in eight East African countries using the panel data regression technique. The association between total healthcare expenditures and life expectancy at birth is presented in Table 3, with Panels A-C using fixed effects regressions. Panel A reveals a strong, positive relationship between the variables LET and HE. For example, an increase in total healthcare expenditures (by private and public entities) by 10 percent leads to an increase in yearly life expectancy at birth by a beta coefficient of 0.0117 on average for the countries in the study. These results align the findings of Aisa et al. ${ }^{16}$ and Jaba et al. ${ }^{15}$, who showed that increases in healthcare expenditures correlate with an increase in life expectancy. In Panels B and C, we repeated the investigation with separate groups for females and males. Panel B shows the relationship between healthcare expenditures and female life expectancy at birth. The results indicated a strong association; a 10 percent increase health expenditure was associated with an increase in yearly female life expectancy by a beta coefficient of 0.0112 on average for the countries in the study. The results in Panel C show a positive correlation for male life expectancy, yet the response is not as strong as for females, with a beta coefficient of 0.0022 . Therefore, female life expectancy at birth responds more significantly to an increase in healthcare expenditures.

\begin{tabular}{|c|c|c|c|c|}
\hline \multicolumn{5}{|c|}{ Panel A: Life expectancy at birth and healthcare expenditures } \\
\hline LET & Coef. & Std. Err. & $\mathrm{z}$ & $\mathrm{P}>|\mathrm{t}|$ \\
\hline $\mathrm{HE}$ & 1.174652 & 0.2190616 & 5.36 & 0.000 \\
\hline Cons & 50.23245 & 1.305135 & 38.49 & 0.000 \\
\hline $\mathrm{F}(1,111)$ & 28.75 & & & \\
\hline Prop. $>\mathrm{F}$ & 0.0000 & & & \\
\hline R-sq & 0.5463 & & & \\
\hline \multicolumn{5}{|c|}{ Panel B: Female life expectancy at birth and healthcare expenditures } \\
\hline LEF & Coef. & Std. Err. & $\mathrm{Z}$ & $\mathrm{P}>|\mathrm{t}|$ \\
\hline $\mathrm{HE}$ & 1.125078 & 0.2230865 & 5.04 & 0.000 \\
\hline Cons & 52.39388 & 1.329114 & 39.42 & 0.000 \\
\hline $\mathrm{F}(1,111)$ & 25.43 & & & \\
\hline Prop. $>\mathrm{F}$ & 0.0000 & & & \\
\hline R-sq & 0.3317 & & & \\
\hline \multicolumn{5}{|c|}{ Panel C: Male life expectancy at birth and healthcare expenditures } \\
\hline LEM & Coef. & Std. Err. & $\mathrm{Z}$ & $\mathrm{P}>|\mathrm{t}|$ \\
\hline $\mathrm{HE}$ & 0.221866 & 0.218089 & 5.60 & 0.000 \\
\hline Cons & 48.17395 & 1.29934 & 37.08 & 0.000 \\
\hline $\mathrm{F}\{1,111)$ & 31.39 & & & \\
\hline Prop. $>\mathrm{F}$ & 0.0000 & & & \\
\hline R-sq & 0.6371 & & & \\
\hline
\end{tabular}

Source: Authors calculation based on data from world development indicators 
Table 4 illustrates the relationship between healthcare expenditures and the number of infant deaths on average for the countries in the study. The results show a negative relationship between healthcare expenditures and the number of infant deaths; an increase in healthcare expenditures by 10 percent are associated with a reduction in the number of infant deaths by a beta coefficient of $5.39(-0.0539 * 100$, since we transformed the number into a logarithm). These findings are similar to those of Gani (26) and Anyanwu and Erhijakpor (4), who documented that an increase in healthcare care spending correlated with a reduction in infant deaths.

\begin{tabular}{|l|l|l|l|l|}
\hline \multicolumn{5}{|l|}{ Table 4: Number of infant deaths and healthcare expenditures } \\
\hline LNID & Coef. & Std. Err. & $\mathrm{Z}$ & $\mathrm{P}>|\mathrm{t}|$ \\
\hline HE & -0.0539784 & 0.0115009 & -4.69 & 0.000 \\
\hline Cons & 11.05084 & 0.0685206 & 161.28 & 0.000 \\
\hline F(1,111) & 22.03 & & & \\
\hline Prop. $>$ F & 0.0000 & & & \\
\hline R-sq & 0.0148 & & & \\
\hline
\end{tabular}

Source: Authors calculation based on data from world development indicators

In Table 5, we ran the test again to observe the relationship between healthcare expenditures and the number of under-five deaths. The results reveal a strong, negative relationship between those variables. According to the mod- el, an increase in healthcare expenditures by 10 percent is associated with a reduction in the number of under-five deaths by a beta coefficient of $6.488(-.0648839 * 100)$ on average for the countries in the study.

\begin{tabular}{|l|l|l|l|l|}
\hline \multicolumn{6}{|l|}{ Table 5: Number of under-five deaths and healthcare expenditures } \\
\hline LNOUFD & Coef. & Std. Err. & z & P $>|t|$ \\
\hline HE & -.0648839 & .0134603 & -4.82 & 0.000 \\
\hline Cons & 11.5212 & .0801941 & 143.67 & 0.000 \\
\hline F(1,111) & 23.24 & & & \\
\hline Prop. $>$ F & 0.0000 & & & \\
\hline R-sq & 0.1731 & & & \\
\hline
\end{tabular}

Source: Authors calculation based on data from world development indicators

Lastly, Table 6 shows the relationship between healthcare expenditures and the number of neonatal deaths. Healthcare spending is negatively correlated with the number of neonatal deaths, as a 10 percent increase in healthcare spending corresponds to a decline in deaths of babies within the first 28 days of life by a beta coefficient of $2.19(-0.0219088 * 100)$. For all our regression analyses, we have reported the F-statistics and the $\mathrm{R}$-squared values, which test whether the model is suitable and techniques are acceptable.

\begin{tabular}{|l|l|l|l|l|}
\hline \multicolumn{6}{|l|}{ Table 6: Number of neonatal deaths and healthcare expenditures } \\
\hline LNON & Coef. & Std. Err. & $\mathrm{z}$ & $\mathrm{P}>|\mathrm{zt}|$ \\
\hline HE & -0.0219088 & 0.0072899 & -3.01 & 0.003 \\
\hline Cons & 10.18688 & 0.0434321 & 234.55 & 0.000 \\
\hline F $(1,111)$ & 9.03 & & & \\
\hline Prop. $>$ F & 0.0033 & & & \\
\hline R-sq & 0.027 & & & \\
\hline
\end{tabular}

Source: Authors calculation based on data from world development indicators

\section{Conclusion}

This paper investigates the relationship between healthcare expenditures and health outcomes using panel techniques for eight East African countries (Burundi, Eritrea,
Ethiopia, Kenya, Rwanda, Sudan, Tanzania, and Uganda). Health outcomes in the study are defined as improved life expectancy at birth and the reduction in the number of neonatal, infant, and under-five deaths. Annual data from 
2000 to 2014 is utilized to examine the relationship. Using fixed effects regressions, we came to several conclusions. First, we found a positive relationship between healthcare expenditures and life expectancy at birth. In addition to this, the relationship was robust for both female and male life expectancy; however, the results revealed that life expectancy for females responded more strongly than that of males to increases in healthcare expenditures. Second, the results show a negative relationship between healthcare expenditures and the number of neonatal, infant, and under-five deaths. Thus, an increase Thus, increases in government and private health expenditures possibly play an important role in reducing neonatal, infant, and under-five deaths.

The above results have important implications for the governmental institutions within the eight East African countries under study. Effective and efficient allocation of resources for healthcare provision is vital, and our empirical findings could be used for setting and enhancing healthcare expenditures. We argue that governments in the eight countries under study must increase their allocated budgets for the health sector to achieved lower mortality and higher life expectancy, thereby catching up with developed economies. For business owners, investing more in private institutions such as hospitals and clinics is essential for favourable health outcomes in these countries. Lastly, the results of our study can be used by the World Health Organization as well as other non-governmental organizations in assisting East African countries. However, future research must examine the separate effects of public and private healthcare expenditures on health outcomes in these eight East African countries and all other African countries. This will answer the question of which type of expenditure is more strongly associated with improved health outcomes.

\section{References}

1. Anton SG, Onofrei, M. Health care performance and health financing systems in countries from central and Eastern Europe. Transylvanian Review of Administrative Sciences 2012; 35: 22-32

2. Kabir M. Determinants of life expectancy in developing countries. The Journal of Developing Areas 2008; 41: 185-204

3. Werblow A, Felder S, Zweifel P. Population ageing and health care expenditure: a school of 'red herrings'?, Health Economics 2007; 16: 1109-26
4. Babazono A, Hillman A. A comparison of international health outcomes and health care spending. Int J Technol Assess Health Care 1994; 10: 40-53

5. Barlow R, Vissandjee B. Determinants of national life expectancy. Canadian Journal of Development Studies 1999; 20: 9-28

6. Cremieux PY, Ouellette P, Pion C. Health care spending as determinants of health outcomes. Health Econ 1999; 8: 627-39

7. Or Z. Determinants of health outcomes in industrials countries: a pooled, cross-country, time-series analysis. OECD Economic Studies 2000; 30: 53-78

8. Wolfe BL. Health status and medical expenditures: is there a link? Soc Sci Med 1986; 22: 993-999

9. Wolfe BL, Gabay M. Health status and medical expenditures: more evidence of a link. Soc Sci Med 1987; 25: 883-888

10. McKenbach JP. Health care expenditure on mortality from amenable conditions in the European community. Health Policy. 199; 19: 245-256

11. Elola J, Daponte A, Navarro V. Health indicators and the organization of health care systems in western Europe. American Journal of Public Health 1995; 85 (10): 1397-1401

12. Seshamani M, Gray A. Ageing and healthcare expenditure: the red herring argument revisited. Health Economics 2004; 13: 303-14

13. Zweifel P, Felder S, Meiers M. Ageing of population and health care expenditure: a red herring? Health Economics 1999; 8: 485-96

14. Cochrane A, St Leger A, Moore F. Health care service input and mortality output in developed countries. J Epidemiol Community Health 1978; 32: 200-205

15. Jaba E, Balan JB, Robu IB. The relationship between life expectancy at birth and health expenditures estimated by a cross-country and time-series analysis. Procedia Economics and Finance 2014; 15:108-14

16. Aisa R, Clemente J, and Pueyo F. The influence of health expenditure on longevity: a reconsideration. International Journal of Public Health 2014; 59 (5): 867-875

17. Akinci F, Hamidi S, Suvankulov F, Akhmedjonov A. Examining the impact of health care expenditures on health outcomes in the Middle East. N. Africa. Journal of Healthcare Finance 2014; 41 (1)

18. Anyanwu JC, Andrew EO. Health expenditures and health outcomes in Africa. African Development Review 2009; 400-33

19. Mays GP, Smith SA. Evidence links increases in public 
health spending to declines in preventable deaths. Health Affairs 2011; 30(8): 1585-93

20. Maruthappu M, Zhou DC, Williams C, Zeltner T, Atun R. Unemployment, public-sector health care expenditure and HIV mortality: an analysis of 74 countries, 1981-2009. Journal of Global Health 2015; 5(1)

21. Nixon J, Ulmann P. The relationship between health care expenditure and health outcomes. European Journal of Health Economics 2006; 7: 7-18

22. Vavken P, Pagenstert G, Grimm C, Dorotka R. Does increased health care spending afford better health care outcomes? Evidence from Austrian health care expenditure since the implementation of DRGs. Swiss Med Weekly 2002; 142:w13589

23. Farag M, Nandakumara AK, Wallack S, Hodgkin D, Gaumer G, Erbil C. Health expenditures, health outcomes and the role of good governance. International Journal of Health Care Finance Economics 2013; 13, 33-52

24. Gupta S, Verhoeven M, Tiongson E. The effectiveness of government spending on education and health care in developing and transition economies. European Journal of Political Economy 2002; 18(4): 717-37

25. Granlund $D$. The effect of health care expenditure on sickness absence. The European Journal of Health Economics 2010; 11: 555-568
26. Gani A. Health care financing and health outcomes in Pacific Islands countries. Health Policy and Planning 2008;

24 (1): $72-81$

27. Hopkins S, Cumming J. The impact of changes in private health expenditure on New Zealand households. Health Policy 2001; 58: 215-229

28. Tountas Y, Karnaki P, Pavi E. Reforming the reform: the Greek national health system in transition. Health Policy 2002; 62: 15-29

29. Siskou O, Kaitelidou D, Papakonstantinou V, Liaropoulos L. Private health expenditure in the Greek health care system: where truth ends and the myth begins. Health Policy 2008; 88: 282-293

30. Wooldridge, Jeffrey M. Introductory econometrics: a modern approach. 3rd ed. Cengage Learning International, 2006

31. Bayati M, Akbarian R, Kavosi Z. Determinants of Life Expectancy in Eastern Mediterranean Region: A Health Production Function. International Journal of Health Policy and Management 2013; 1(1): 65-71

32. Berger CM, Messer J. Public financing of health expenditures, insurance, and health Outcomes. Applied Economics 2002; 34 (17): 2105-2113 